\title{
Predictive Values of Self-Reported Periodontal Need: National Health and Nutrition Examination Survey III
}

\author{
Monica A. Fisher, ${ }^{*}$ George W. Taylor, ${ }^{\dagger}$ Brent J. Shelton, ${ }^{\ddagger}$ and Sara M. Debanne $§$
}

Background: This study assessed predictive values of self-reported periodontal need to identify periodontal conditions using clinical examinations as the gold standard.

Methods: We identified 12,370 adults $\geq 18$ years of age in the third National Health and Nutrition Examination Survey. Self-reported periodontal need was based on participants responding that gum treatment and/or cleaning was needed when asked: "What type of dental care do you need now?" Two periodontal conditions were at least two sites with pockets (pockets $\geq 3 \mathrm{~mm}$ or pockets $\geq 4 \mathrm{~mm}$ ) and at least two sites with calculus. Main outcomes were: 1 ) positive predictive value $\left(\mathrm{PPV}_{\text {Clean }}\right)$ : proportion of those who self-reported the

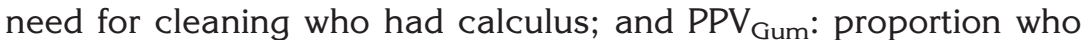
self-reported the need for gum treatment who had pockets; 2) negative predictive value $\left(\mathrm{NPV}_{\text {Clean }}\right)$ : proportion of those who selfreported no need for cleaning who did not have calculus; and $\mathrm{NPV}_{\text {Gum }}$ : proportion who self-reported no need for gum treatment who did not have pockets; 3) association between predictive values and sociodemographic and behavioral characteristics; and 4) proportion of individuals with specific sociodemographic and behavioral characteristics whose self-reported periodontal need predicted periodontal conditions.

Results: The prevalence of periodontal conditions influenced predictive values. Calculus prevalence $=85 \%$ : corresponding $\mathrm{PPV}_{\mathrm{Clean}}=$ $88 \%$ and $\mathrm{NPV}_{\text {Clean }}=16 \%$. Prevalence of pockets $\geq 3 \mathrm{~mm}=47 \%$ : corresponding $P P V_{\text {Gum }}=62 \%$ and $N P V_{\text {Gum }}=54 \%$. Prevalence of pockets $\geq 4 \mathrm{~mm}=11 \%$ : corresponding $\mathrm{PPV}_{\mathrm{Gum}}=25 \%$ and $\mathrm{NPV}_{\mathrm{Gum}}=90 \%$. Ninety percent of 30- to 44-year-old minority female smokers who did not visit the dentist in the past year and reported the need for gum treatment had pockets $\geq 3 \mathrm{~mm}\left(\mathrm{PPV}_{\mathrm{Gum}}=90 \%\right)$.

Conclusions: Self-reported periodontal need (cleaning/gum treatment) predicted the presence of the prevalent conditions (calculus/ pockets $\geq 3 \mathrm{~mm}$ ). Not reporting a need for periodontal treatment predicted the absence of the less common condition (pockets $\geq 4 \mathrm{~mm}$ ) but not the more prevalent condition (calculus). J Periodontol 2007;78: 1551-1560.

\section{KEY WORDS}

Dental calculus; dental prophylaxis; epidemiology; NHANES; oral health; predictive value of tests.

\footnotetext{
* Department of Orthodontics, Case Western Reserve University, Cleveland, OH.

$\dagger$ Department of Cariology, Restorative Sciences, and Endodontics, University of Michigan, Ann Arbor, MI.

\# Departments of Internal Medicine and Biostatistics, University of Kentucky, Lexington, KY.

$\S$ Department of Epidemiology and Biostatistics, Case Western Reserve University.
}

1 The validity of self-reported measures for surveillance of periodontal disease has been advanced by a working group organized by the Oral Health Division of the Centers for Disease Control and Prevention (CDC) and the American Academy of Periodontology (AAP) in light of the fact that nationally representative periodontal examination data are no longer collected as a component of the National Health and Nutrition Examination Survey (NHANES). ${ }^{1}$ Although periodontal assessment is not a component of the National Oral Health Surveillance System developed by CDC and the Association of State and Territorial Dental Directors, Beltran-Aguilar et al. ${ }^{2}$ indicated there is a need to test the validity of self-report by seniors and to develop a screening protocol for periodontal disease. Positive preliminary findings regarding the current development of national surveillance of periodontal conditions in the United States population, based on selfreport, ${ }^{3}$ raises the question of whether self-reported periodontal condition is valid on an individual level.

Validity of self-reported symptoms, presence of periodontal disease, or recollection of being

doi: 10.1902/jop.2007.060395 
diagnosed or receiving treatment for periodontal disease to determine periodontal disease status has focused on the sensitivity, specificity, positive predictive value (PPV), and negative predictive value (NPV). ${ }^{4}$ Sensitivity and specificity indicate how good a test correctly identifies those with and without disease; hence, providing a way to evaluate the validity of self-report to estimate population prevalence of periodontal conditions. Sensitivity answers an important public health question. ${ }^{5}$ If we ask a group of individuals about their periodontal condition, what proportion of those who have periodontal disease will be identified correctly? In the context of our study, sensitivity is defined as the proportion of those who have periodontal disease who are identified correctly through self-reported periodontal needs. Specificity is the proportion of those who do not have periodontal disease and are identified correctly through self-report that they do not have periodontal needs. Thus, the values for sensitivity and specificity are based on knowing whether an individual has the periodontal condition, then determining the probability that he/ she will report the corresponding periodontal need.

In the clinical setting, the PPV can provide information that is important to the clinician. ${ }^{5}$ If an individual reports having a need for periodontal therapy, such as cleaning or gum treatment, PPV answers the question, "What is the probability that this patient has the corresponding periodontal condition?" That is, PPV estimates the probability of truly having calculus or pockets if a person reports needing a cleaning or gum treatment. NPV estimates the probability of not having calculus or pockets if a person reports that they do not need their teeth cleaned or gum treatment. Hence, predictive values are relevant measures when investigating the validity of questions to predict an individual's periodontal condition. Our report presents the direct application of predictive values to an individual, by estimating the probability that an individual with specific sociodemographic and behavioral characteristics who reports having or not having a periodontal need, will or will not have the periodontal condition.

In addition to recognizing the importance of PPV and NPV, we must introduce a very important distinction between surveillance or population estimates versus the predictive values of self-reported periodontal conditions on an individual level. The CDC/AAP Working Group has been investigating the validity of selfreported periodontal conditions on a population level, whereas our study focused on the predictive values of self-reported periodontal conditions on an individual level. Next, we illustrate this crucial distinction via previously published data.

Dietrich et al. ${ }^{6}$ reported that $39 \%$ of the subjects truly had periodontal disease based on radiographic alveolar bone loss and 39\% self-reported that they had periodontitis or periodontal disease. At the surveillance or population level, self-reported periodontal disease was excellent in identifying the prevalence of periodontal disease with exactly the same prevalence resulting from the radiographic examination and self-report. However, many of the individuals reporting that they had periodontal disease were not the same individuals with radiographically determined periodontal disease (PPV $=49 \%)$. Likewise, many of the individuals reporting that they did not have periodontal disease were not the same individuals without radiographically determined periodontal disease (NPV $=67 \%$ ). Thus, among 20 - to 80 -year-olds, self-reported periodontal disease was not satisfactory in identifying an individual's periodontal condition. Another study ${ }^{7}$ of older adults found self-reported oral health problems were not correlated with clinical measures of periodontal disease.

Conversely, among health professionals, selfreported history of periodontal disease was reported to be an acceptable measure for radiographic alveolar bone loss, with PPV of $76 \%$ and NPV of $74 \%$ for dentists $^{8}$ and PPV of $83 \%$ and NPV of $69 \%$ for nondentists. $^{9}$ An additional study ${ }^{10}$ found PPV of $77 \%$ for self-reporting that a dentist or dental hygienist told them that they had deep pockets and NPV of $76 \%$ for self-reporting that a dentist or dental hygienist did not tell them that they had deep pockets.

The objectives of our study were to assess 1 ) the predictive values of self-reported periodontal need for dental cleaning to identify those with and without calculus; 2 ) the predictive values of self-reported need for gum treatment to identify those with and without pockets; 3 ) the association between predictive values and sociodemographic (i.e., age, minority status, gender, education, and income) and behavioral characteristics (i.e., smoking and annual dentist visit); and 4 ) the proportion of individuals with selected sociodemographic and behavioral characteristics whose selfreported periodontal need predicted their periodontal condition.

\section{MATERIALS AND METHODS}

\section{Study Population}

This study used the public-use NHANES III crosssectional survey in compliance with the Data Use Restrictions for data collected by the National Center for Health Statistics, CDC. The NHANES III is a rich source of health/disease and risk factor data representative of the United States population obtained from a well-designed and well-conducted study during 1988 to 1994 . NHANES III is a complex, multistage, stratified, clustered sample of the civilian, non-institutionalized United States population $\geq 2$ years of age. ${ }^{1}$ The NHANES III includes in-person questionnaires, 
laboratory assays, and clinical examination measures of health outcomes and potential explanatory variables. The questionnaire included a vast array of data; some of the data relevant to this research study are age, race/ethnicity, gender, education, income, and last dental visit. We identified 12,370 adults $\geq 18$ years of age with self-reported periodontal need, cotinine laboratory data, and dental examination data for the presence/absence of calculus and probing depth in NHANES III.

\section{Description of the Main Outcomes: Predictive Values of Self-Reported Periodontal Need to Predict Periodontal Condition}

We compared two distinct measures of periodontal condition: self-reported periodontal need and clinical examination of periodontal condition. Self-reported periodontal need was based on participants' multiple responses to the question: "What type of dental care do you need now?" Two of the 10 dental needs included in the questionnaire were cleaning and gum treatment. Each individual's periodontal condition was based on their dental examination. The presence of calculus was defined as having two or more sites with calculus. Because the presence of calculus indicates that a dental cleaning is needed, the predictive value of the self-reported need for a cleaning was assessed by comparing each individual's response to the clinically assessed or "true" presence or absence of any calculus at two or more sites.

Similarly, the presence of pockets indicates that gum treatment is needed. The recommendation for referral for care in the NHANES examination protocol was for participants to seek dental care at their earliest convenience when there were two or more sites with pockets $>4 \mathrm{~mm} .{ }^{11}$ We used a more conservative definition of probing depth using two separate definitions: pockets $\geq 3$ and pockets $\geq 4 \mathrm{~mm}$. Thus, the predictive value of the self-reported need for gum treatment was assessed by comparing each participant's self-reported need for gum treatment (yes/no) to the clinical examination finding: the more prevalent measure of two or more sites with pockets $\geq 3 \mathrm{~mm}$ and the more severe but less prevalent measure of two or mores sites with pockets $\geq 4 \mathrm{~mm}$ (yes/no). In addition to the influence of potential explanatory sociodemographic and behavioral variables, both of these definitions were assessed because of the additional influence of the prevalence of periodontal condition on predictive values; more prevalent diseases have higher PPV and lower NPV, ${ }^{5}$ and less common diseases have higher NPV and lower PPV. ${ }^{12}$

Individuals who have calculus need a dental cleaning and those with pockets need gum treatment. Thus, the four main outcomes were 1) PPV Clean, defined as the proportion of those who self-reported the need for cleaning who had calculus; 2) $P P V_{\text {Gum }}$, defined as the proportion of those who self-reported a need for gum treatment who had pockets $\geq 3$ or $\geq 4 \mathrm{~mm}$; 3) $\mathrm{NPV}_{\text {Clean }}$, defined as the proportion of those who did not report that they needed a cleaning who did

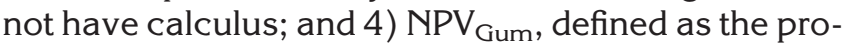
portion of those who did not self-report a need for gum treatment who did not have pockets $\geq 3 \mathrm{~mm}$ or $\geq 4 \mathrm{~mm}$.

\section{Description of Potential Sociodemographic and Behavioral Explanatory Variables}

To the best of our knowledge, our study is the first to assess the potential role of sociodemographic and behavioral characteristics on the estimated predictive values of self-reported periodontal need to predict periodontal condition. Previous reports were limited to estimates of an overall predictive value for the specific study sample. Thus, the potential sociodemographic and behavioral explanatory variables for predictive values included those previously recognized as risk factors for periodontal disease: current smoker (yes/no, based on serum cotinine $\geq 15 \mathrm{ng} / \mathrm{ml}$, this objective measure was used as the "true" measure of smoking rather than self-reported smoking which may not be valid), ${ }^{13}$ age (18 to 29 years, 30 to 44 years, and $\geq 45$ years), race/ethnicity (minority or non-Hispanic white; non-Hispanic black, MexicanAmericans, and other race/ethnicity categories were collapsed into minority because the results were essentially the same for these three groups with respect to the parameter estimates for cleaning need and for gum treatment need), gender, high school graduate (yes/no), annual income $(<\$ 20,000$ or $\geq \$ 20,000)$, and having a dental visit in the past year (yes/no).

\section{Statistical Methods}

The NHANES III complex survey design and sample weights were taken into account in the data analyses using software packages. ${ }^{14 \mid \text { II }}$ In this study of the predictive values for self-reported periodontal need to predict or identify the periodontal condition, we speculated that the predictive values may be higher for certain subgroups. Hence, we tested the hypothesis that predictive values of self-reported periodontal need to identify the periodontal condition varied with sociodemographic and behavioral characteristics. Specifically, the null hypothesis was that PPV/NPV of self-reported periodontal need was not dependent on age, minority status, gender, education, income, smoking status, or having a dentist visit in the past year.

The overall predictive values $\left(\mathrm{PPV}_{\mathrm{Clean}}, \mathrm{PPV}_{\mathrm{Gum}}\right.$, $N P V_{\text {Clean }}$, and $N P V_{\text {Gum }}$ ) were calculated for all participants. The independent association between the main

\| SUDAAN release 9.0.1, Research Triangle Institute, Research Triangle Park, NC. II SAS, version 9.1, SAS Institute, Cary, NC. 
outcome or dependent variable, i.e, the predictive values $\left(P P V_{\text {Clean }}, P P V_{G u m}, N P V_{\text {Clean }}\right.$, and $\left.N P V_{G u m}\right)$, and the potential explanatory variables or independent variables, i.e., sociodemographic and behavioral characteristics, was quantified by calculating the adjusted odds ratio $\left(\mathrm{OR}_{\mathrm{Adj}}\right)$, simultaneously taking into account the statistically significant explanatory variables, with statistical significance reported as 95\% confidence interval $(\mathrm{CI})$. A separate multivariable (one dependent variable and multiple independent variables) logistic regression model was developed for all adults, minority and non-Hispanic white adults.

The estimate of the probability $(\pi(\mathrm{x}))$ that an individual with specific characteristics (covariates in multiple logistic regression model ${ }^{15}$ will be identified correctly with respect to periodontal condition based on self-reported periodontal need (i.e., PPV Clean, $P P V_{G u m}, N P V_{\text {Clean }}$, and $N P V_{\text {Gum }}$ ) was calculated using the formula

$$
\pi(x)=\frac{e^{\beta_{0}+\beta_{1} X_{1}+\cdots+\beta_{7} X_{7}}}{1+e^{\beta_{0}+\beta_{1} X_{1}+\cdots+\beta_{7} X_{7}}}
$$

where $\beta_{0}$ is the intercept, $\beta_{1}$ is the beta coefficient for the first independent variable $\left(x_{1}\right), \beta_{2}$ is the beta coefficient for the second independent variable $\left(\mathrm{x}_{2}\right)$, and so forth for each independent variable in the multivariable model. The beta coefficients in the multivariable logistic regression models were used to estimate the probability that individuals with specific characteristics who reported that they needed a cleaning actually had clinically assessed calculus, and those who reported that they needed gum treatment actually had clinically assessed pockets. We report herein the two extreme scenarios representing the range of values.

\section{RESULTS}

\section{Predictive Values of Self-Reported Need for Dental} Cleaning to Identify Those With Calculus

For all subjects $\geq 18$ years of age, $88 \%$ of those who self-reported that they needed a dental cleaning had calculus $\left(\mathrm{PPV}_{\text {Clean }}\right)$, and $12 \%$ did not have calculus. Sixteen percent of those who did not report that they needed a cleaning did not have calculus $\left(\mathrm{NPV}_{\text {Clean }}\right)$, and $84 \%$ had calculus (Table 1 ).

\section{Predictive Values of Self-Reported Need for Gum Treatment to Identify Those With Pockets}

For all subjects $\geq 18$ years of age, $62 \%$ of those who self-reported that they needed gum treatment had pockets $\geq 3 \mathrm{~mm}$ (PPV $\mathrm{Gum}_{\mathrm{m}}$ ), and $38 \%$ did not have pockets $\geq 3 \mathrm{~mm}$. Fifty-four percent of those who did not report that they needed gum treatment did not have pockets $\geq 3 \mathrm{~mm}$ (NPV Gum), and $46 \%$ had pockets $\geq 3 \mathrm{~mm}$. Twenty-five percent of those who self-reported that they needed gum treatment had pockets $\geq 4 \mathrm{~mm}$ (PPV Gum $)$, and $75 \%$ did not have pockets $\geq 4 \mathrm{~mm}$. Ninety percent of those who did not report that they needed gum treatment did not have pockets $\geq 4 \mathrm{~mm}$ (NPV $\mathrm{Gum}_{\text {) }}$ ), and $10 \%$ had pockets $\geq 4 \mathrm{~mm}$ (Table 1 ).

\section{Multivariable Logistic Regression Models of the Association Between Self-Reported Cleaning Need Predicting Presence of Calculus and} Sociodemographic and Behavioral Characteristics When we described the main outcomes in the previous section, we indicated that predictive values are influenced by the prevalence of the condition, with an inverse relationship between PPV and NPV. Because of this inverse relationship between NPV and PPV, the

Table I.

\section{Self-Reported Periodontal Need Predicts Periodontal Condition, United States Adults}

\begin{tabular}{|c|c|c|}
\hline & \multicolumn{2}{|c|}{ Need Cleaning Among Subjects $\geq 18$ Years Old } \\
\hline \multirow{3}{*}{$\begin{array}{l}\text { Yes } 84.8 \% \\
\text { No } 15.2 \%\end{array}$} & 3,$204 ; 88.3 \%$ PPV $_{\text {Clean }}$ & 7,$730 ; 83.6 \%$ \\
\hline & $373 ; 11.7 \%$ & I,063; I6.4\% NPV Clean \\
\hline & \multicolumn{2}{|c|}{ Need Gum Treatment Among Subjects $\geq 18$ Years Old } \\
\hline \multicolumn{3}{|l|}{ Pocket $\geq 3 \mathrm{~mm}$} \\
\hline Yes $46.6 \%$ & $620 ; 61.5 \% \mathrm{PPV}_{\mathrm{Gum}}$ & 6,$257 ; 45.6 \%$ \\
\hline No $53.4 \%$ & $267 ; 38.5 \%$ & 5,$226 ; 54.4 \%$ NPV $_{\text {Gum }}$ \\
\hline \multicolumn{3}{|l|}{ Pocket $\geq 4 \mathrm{~mm}$} \\
\hline
\end{tabular}

Number of individuals $(\mathrm{n})$ are unweighted with weighted \%. 
opposite characteristic (i.e., non-smoking) will be associated with NPV rather than the characteristic associated with PPV (i.e., smoking); therefore, a separate model was developed for PPV and NPV. For example, if smokers who report needing a cleaning are more likely to have calculus than those who do not smoke $\left(P P V_{\text {Clean }}\right)$, the inverse association would be expected when estimating the $\mathrm{NPV}_{\text {Clean }}$ where non-smokers who do not report needing a cleaning would be more likely to not have calculus than those who smoke.

$\mathrm{PPV}_{\text {Clean }}$ was defined as the ability of an individual's self-reported need for a dental cleaning to predict having calculus present, based on the actual clinically assessed status being the "gold standard." The prediction of the presence of calculus based on reporting that a cleaning was needed was associated with age, gender, current smoking status, and having a dentist visit in the past year, after simultaneously taking into account all of the listed characteristics. Self-reported need for a cleaning was 1.5 to 2.5 times more likely to predict the presence of calculus in adults $\geq 45$ years old (OR Adj: $_{1.83 ;} 95 \% \mathrm{CI}: 1.16$ to 2.09), males (OR ${ }_{\text {Adj: }}$ : 1.54; $95 \%$ CI: 1.06 to 2.24$)$, smokers $\left(\mathrm{OR}_{\mathrm{Adj}}\right.$ : 2.50; 95\% CI: 1.53 to 4.06 ), and those who did not visit the dentist in the past year $\left(\mathrm{OR}_{\mathrm{Adj}}: 2.66 ; 95 \% \mathrm{CI}\right.$ : 1.71 to 4.12 ) than in younger adults, females, nonsmokers, and those who visited the dentist in the past year (Table 2). In the separate models for minority and non-Hispanic white adults, visiting the dentist in the past year had a much greater association with the odds of having calculus in non-Hispanic white adults; they were 3.5 times more likely to have calculus (OR Adj: 3.38; $95 \% \mathrm{CI}: 1.85$ to 6.19 ) than their nonHispanic white counterparts who did not visit the dentist in the past year, whereas having a dental visit in the past year was not statistically significant in the model restricted to minority adults.

$\mathrm{NPV}_{\text {Clean }}$ was associated with age, minority status, gender, education, income, current smoking status, and having a dentist visit in the past year. Among all subjects $\geq 18$ years of age, not reporting a dental cleaning was needed was 1.5 to 3 times more likely to predict the absence of calculus in younger subjects (18- to 29-year-olds $\mathrm{OR}_{\mathrm{Adj}}$ : 2.42; $95 \% \mathrm{CI}: 1.79$ to 3.28; 30 - to 44 -year-olds OR $\mathrm{O}_{\text {Adj }}$ : 1.56 ; $95 \% \mathrm{CI}: 1.18$ to 2.05$)$, non-Hispanic whites (OR $\mathrm{ORdj}_{\mathrm{Adj}}$ : $2.15 ; 95 \% \mathrm{CI}$ : 1.72 to 2.67$)$, females (OR ${ }_{\text {Adj: }}: 1.36 ; 95 \% \mathrm{CI}: 1.13$ to $1.65)$, high school graduates $\left(\mathrm{OR}_{\mathrm{Adj}}: 1.47 ; 95 \% \mathrm{CI}\right.$ : 1.12 to 1.94$)$, current non-smokers (OR ${ }_{\text {Adj: }} 1.90$; 95\% CI: 1.39 to 2.60 ), and those who had visited the dentist in the past year $\left(\mathrm{OR}_{\mathrm{Adj}}: 2.30 ; 95 \% \mathrm{CI}\right.$ : 1.64 to 3.23$)\left(\mathrm{NPV}_{\text {Clean }}\right)$. In the separate models for minority and non-Hispanic white adults, the strength of the association was stronger for minority adults than for non-Hispanic white adults for each significant characteristic, except for age and smoking.
Multivariable Logistic Regression Models of the Association Between Self-Reported Gum Treatment Need Predicting Pockets and Sociodemographic and Behavioral Characteristics

The prediction of the presence of pockets based on reporting gum treatment was needed was associated with minority status, current smoking, and having a dentist visit in the past year. Self-reported need for gum treatment was two to three times more likely to predict the presence of pockets $\geq 3 \mathrm{~mm}$ in minorities

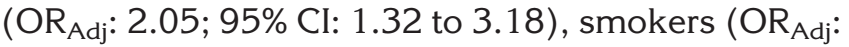
1.78; $95 \%$ CI: 1.09 to 2.89 ), and those who did not visit the dentist in the past year (OR $\mathrm{ORdj}_{\text {: }}$ : $.61 ; 95 \% \mathrm{CI}: 1.38$ to 4.94) ( $\left.\mathrm{PPV}_{\mathrm{Gum}}\right)$ than in non-Hispanic white adults, non-smokers, and those who visited the dentist in the past year (Table 3 ). In the separate models for minority and non-Hispanic white adults, smoking was not statistically significant for minority adults, and age was not statistically significant for non-Hispanic white adults.

$\mathrm{NPV}_{\text {Gum }}$ was associated with age, minority status, gender, education, income, current smoking status, and having a dentist visit in the past year. Among all subjects $\geq 18$ years of age, not reporting a need for gum treatment was 1.5 to 2.5 times more likely to predict the absence of pockets $\geq 4 \mathrm{~mm}$ in younger adults (18- to 29-year-olds $\mathrm{OR}_{\mathrm{Adj}}$ : 2.00; 95\% CI: 1.55 to 2.58 ; 30 - to 44 -year olds $\mathrm{OR}_{\text {Adj: }}: 1.25 ; 95 \%$ CI: 0.98 to 1.60$)$, non-Hispanic whites ( $\mathrm{OR}_{\mathrm{Adj}}$ : 1.88 ; 95\% CI: 1.40 to 2.51 ), females (OR $\mathrm{ORdj}$ : $1.58 ; 95 \%$ CI: 1.29 to 1.95$)$, high school graduates $\left(\mathrm{OR}_{\mathrm{Adj}}\right.$ : 1.62; $95 \% \mathrm{CI}: 1.30$ to 2.02 ), persons with an annual income $\geq \$ 20,000\left(\mathrm{OR}_{\mathrm{Adj}}\right.$ : $1.54 ; 95 \% \mathrm{CI}: 1.25$ to

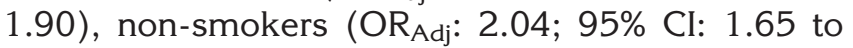
2.53), and those who visited the dentist in the past year ( $\mathrm{OR}_{\text {Adj: }}: 1.47 ; 95 \% \mathrm{CI}: 1.16$ to 1.86$)\left(\mathrm{NPV}_{\mathrm{Gum}}\right)$. The strength of the association was stronger for non-Hispanic white adults than for minority adults.

\section{Proportion of Individuals With Specific Characteristics Who Self-Report They Need a Cleaning Predicts the Presence/Absence of Calculus}

The proportion of individuals with specific sociodemographic and behavioral characteristics who self-reported that they needed a cleaning and had calculus, thus predicting the presence of calculus $\left(\mathrm{PPV}_{\text {Clean }}\right)$, ranged from $70 \%$ of 18 - to 29 -year-old non-Hispanic white female non-smokers who visited the dentist in the past year $\left(\mathrm{PPV}_{\text {Clean }}=70 \%\right)$ to $99 \%$ of $\geq 45$-year-old minority male smokers who did not visit the dentist in the past year $\left(\mathrm{PPV}_{\text {Clean }}=99 \%\right)$ (Table 2). Thus, the self-reported need for a cleaning predicted the presence of calculus.

The proportion of individuals with specific characteristics who did not report that they needed a cleaning 
Table 2.

\section{Multivariable Models for Self-Reported Need for Cleaning Predicting Presence/Absence of Calculus, United States}

\begin{tabular}{|c|c|c|c|c|c|c|}
\hline \multirow[b]{2}{*}{$\begin{array}{l}\text { Independent } \\
\text { Variables }\end{array}$} & \multicolumn{3}{|c|}{$\begin{array}{c}\text { Self-Reported Need for Cleaning } \\
\text { Predicting Presence of Calculus (PPV } \text { Clean }^{\text {) }}\end{array}$} & \multicolumn{3}{|c|}{$\begin{array}{c}\text { Self-Reported No Need for Cleaning } \\
\text { Predicting Absence of Calculus (NPV Clean) }\end{array}$} \\
\hline & $\begin{array}{c}\text { All Adults } \\
\mathrm{OR}_{\text {Adj }}(95 \% \mathrm{Cl})\end{array}$ & $\begin{array}{l}\text { Minority Adults } \\
\mathrm{OR}_{\text {Adj }}(95 \% \mathrm{Cl})\end{array}$ & $\begin{array}{c}\text { Non-Hispanic } \\
\text { White Adults } \\
\text { OR Adj }(95 \% \mathrm{Cl})\end{array}$ & $\begin{array}{c}\text { All Adults } \\
\text { OR }_{\text {Adj }}(95 \% \mathrm{Cl}) \\
\end{array}$ & $\begin{array}{l}\text { Minority Adults } \\
\mathrm{OR}_{\text {Adj }}(95 \% \mathrm{Cl})\end{array}$ & $\begin{array}{c}\text { Non-Hispanic } \\
\text { White Adults } \\
\mathrm{OR}_{\text {Adj }}(95 \% \mathrm{Cl})\end{array}$ \\
\hline \multicolumn{7}{|l|}{ Age (years) } \\
\hline 18 to 29 & 1.00 & 1.00 & 1.00 & $2.42(1.79-3.28)^{*}$ & $2.26(1.46-3.50)^{*}$ & $2.38(1.70-3.31) *$ \\
\hline \multicolumn{7}{|l|}{ Minority } \\
\hline Yes & $1.54(0.95-2.50)$ & - & - & 1.00 & - & - \\
\hline No & 1.00 & & & $2.15(1.72-2.67)^{*}$ & & \\
\hline \multicolumn{7}{|l|}{ Gender } \\
\hline No & & & & 1.00 & 1.00 & 1.00 \\
\hline \multicolumn{7}{|l|}{ Income $<\$ 20,000$} \\
\hline Yes & - & - & - & 1.00 & 1.00 & 1.00 \\
\hline No & & & & $1.27(0.91-1.76)$ & $1.75(1.09-2.80)^{*}$ & $1.17(0.81-1.70)$ \\
\hline \multicolumn{7}{|l|}{ Current smoker } \\
\hline Yes & $2.50(1.53-4.06)^{*}$ & $2.00(1.22-3.29)^{*}$ & $2.69(1.38-5.25)^{*}$ & 1.00 & 1.00 & 1.00 \\
\hline No & 1.00 & 1.00 & 1.00 & $1.90(1.39-2.60)^{*}$ & $1.40(0.90-2.19)$ & $1.97(1.40-2.78) *$ \\
\hline \multicolumn{7}{|c|}{ Dentist visit in past year } \\
\hline Yes & 1.00 & 1.00 & 1.00 & $2.30(1.64-3.23)^{*}$ & $2.71(1.66-4.43)^{*}$ & $2.26(1.54-3.30)^{*}$ \\
\hline No & $2.66(1.71-4.12)^{*}$ & $1.61(0.88-2.96)$ & $3.38(1.85-6.19)^{*}$ & 1.00 & 1.00 & 1.00 \\
\hline
\end{tabular}

- = not included in the final model because not statistically significant or not applicable

* P value $<0.05$

and did not have calculus, thus predicting the absence of calculus $\left(\mathrm{NPV}_{\text {Clean }}\right)$, ranged from $1 \%$ of $\geq 45$-yearold minority male smokers who did not graduate from high school, had an annual income $<\$ 20,000$, and had no dentist visit in the past year $\left(\mathrm{NPV}_{\text {Clean }}=1 \%\right)$ to $38 \%$ of 18 - to 29 -year-old non-Hispanic white female non-smokers who graduated from high school, had an annual income $\geq \$ 20,000$, and visited the dentist in the past year $\left(\mathrm{NPV}_{\text {Clean }}=38 \%\right)$. Thus, not reporting that a cleaning was needed was not a good predictor of the absence of calculus.

\section{Proportion of Individuals With Specific} Characteristics Who Self-Report They Need Gum Treatment Predicts the Presence/Absence of Pockets

In Table 3, the proportion of individuals who reported that they needed gum treatment and had pockets $\geq 3 \mathrm{~mm}$, thus predicting the presence of pockets $\left(P P V_{G u m}\right)$, ranged from $37 \%$ of $\geq 45$-year-old nonHispanic white male non-smokers who visited the dentist in the past year $\left(\mathrm{PPV}_{\mathrm{Gum}}=37 \%\right)$ to $90 \%$ of 30 - to 44-year-old minority female smokers who 
Table 3.

\section{Multivariable Models for Self-Reported Need for Gum Treatment Predicting Presence/Absence of Pockets, United States}

\begin{tabular}{|c|c|c|c|c|c|c|}
\hline \multirow[b]{2}{*}{$\begin{array}{l}\text { Independent } \\
\text { Variables }\end{array}$} & \multicolumn{3}{|c|}{$\begin{array}{l}\text { Self-Reported Need for Gum Treatment } \\
\left.\text { Predicting Presence of Pockets (PPV } \text { Gum }_{\text {( }}\right)\end{array}$} & \multicolumn{3}{|c|}{$\begin{array}{l}\text { Self-Reported No Need for Gum Treatment } \\
\text { Predicting Absence of Pockets (NPV Gum) }\end{array}$} \\
\hline & $\begin{array}{c}\text { All Adults } \\
\mathrm{OR}_{\text {Adj }}(95 \% \mathrm{Cl}) \\
\end{array}$ & $\begin{array}{l}\text { Minority Adults } \\
\mathrm{OR}_{\text {Adj }}(95 \% \mathrm{Cl}) \\
\end{array}$ & $\begin{array}{l}\text { Non-Hispanic } \\
\text { White Adults } \\
\mathrm{OR}_{\text {Adj }}(95 \% \mathrm{Cl}) \\
\end{array}$ & $\begin{array}{c}\text { All Adults } \\
\mathrm{OR}_{\mathrm{Adj}}(95 \% \mathrm{Cl}) \\
\end{array}$ & $\begin{array}{l}\text { Minority Adults } \\
\mathrm{OR}_{\mathrm{Adj}}(95 \% \mathrm{Cl}) \\
\end{array}$ & $\begin{array}{l}\text { Non-Hispanic } \\
\text { White Adults } \\
\text { OR }_{\text {Adj }}(95 \% \mathrm{Cl}) \\
\end{array}$ \\
\hline $\begin{array}{l}\text { Age (years) } \\
\quad 18 \text { to } 29 \\
30 \text { to } 44 \\
\geq 45\end{array}$ & $\begin{array}{l}1.12(0.58-2.16) \\
1.64(0.80-3.38) \\
1.00\end{array}$ & $\begin{array}{l}1.21(0.50-2.91) \\
2.75(1.29-5.84)^{*} \\
1.00\end{array}$ & $\begin{array}{l}1.05(0.41-2.68) \\
1.34(0.54-3.37) \\
1.00\end{array}$ & $\begin{array}{l}2.00(1.55-2.58)^{*} \\
1.25(0.98-1.60) \\
1.00\end{array}$ & $\begin{array}{l}1.58(1.05-2.36)^{*} \\
1.20(0.89-1.62) \\
1.00\end{array}$ & $\begin{array}{l}2.56(1.83-3.59)^{*} \\
1.25(0.90-1.74) \\
1.00\end{array}$ \\
\hline $\begin{array}{l}\text { Minority } \\
\text { Yes } \\
\text { No }\end{array}$ & $\begin{array}{l}2.05(1.32-3.18)^{*} \\
1.00\end{array}$ & - & - & $\begin{array}{l}1.00 \\
1.88(1.40-2.51)^{*}\end{array}$ & - & - \\
\hline $\begin{array}{l}\text { Gender } \\
\text { Male } \\
\text { Female }\end{array}$ & $\begin{array}{l}1.00 \\
1.02(0.57-1.83)\end{array}$ & $\begin{array}{l}1.45(0.82-2.56) \\
1.00\end{array}$ & $\begin{array}{l}0.85(0.39-1.86) \\
1.00\end{array}$ & $\begin{array}{l}1.00 \\
1.58(1.29-1.95)^{*}\end{array}$ & $\begin{array}{l}1.00 \\
1.55(1.21-1.98)^{*}\end{array}$ & $\begin{array}{l}1.00 \\
1.65(1.24-2.20)^{*}\end{array}$ \\
\hline $\begin{array}{l}\text { Income }<\$ 20,000 \\
\text { Yes } \\
\text { No }\end{array}$ & - & - & - & $\begin{array}{l}1.00 \\
1.54(1.25-1.90)^{*}\end{array}$ & $\begin{array}{l}1.00 \\
1.32(0.99-1.75)\end{array}$ & $\begin{array}{l}1.00 \\
1.77(1.33-2.35)^{*}\end{array}$ \\
\hline $\begin{array}{l}\text { Current smoker } \\
\text { Yes } \\
\text { No }\end{array}$ & $\begin{array}{l}1.78(1.09-2.89)^{*} \\
1.00\end{array}$ & $\begin{array}{l}1.18(0.61-2.27) \\
1.00\end{array}$ & $\begin{array}{l}1.98(1.04-3.78)^{*} \\
1.00\end{array}$ & $\begin{array}{l}1.00 \\
2.04(1.65-2.53)^{*}\end{array}$ & $\begin{array}{l}1.00 \\
1.58(1.23-2.03)^{*}\end{array}$ & $\begin{array}{l}1.00 \\
2.33(1.70-3.19)^{*}\end{array}$ \\
\hline $\begin{array}{l}\text { Dentist visit in past year } \\
\text { Yes } \\
\text { No }\end{array}$ & $\begin{array}{l}1.00 \\
2.61(1.38-4.94)^{*}\end{array}$ & $\begin{array}{l}1.00 \\
2.31(1.28-4.18)^{*}\end{array}$ & $\begin{array}{l}1.00 \\
2.87(1.27-6.5 \mathrm{I})^{*}\end{array}$ & $\begin{array}{l}1.47(1.16-1.86)^{*} \\
1.00\end{array}$ & $\begin{array}{l}1.37(1.09-1.72)^{*} \\
1.00\end{array}$ & $\begin{array}{l}1.54(1.05-2.26)^{*} \\
1.00\end{array}$ \\
\hline
\end{tabular}

$-=$ not included in the final model because not statistically significant or not applicable.

* $P$ value $<0.05$.

did not visit the dentist in the past year $\left(\mathrm{PPV}_{\mathrm{Gum}}=\right.$ $90 \%)$. Thus, the self-reported need for gum treatment predicted having pockets $\geq 3 \mathrm{~mm}$ for certain adults with specific sociodemographic and behavioral characteristics.

As shown in Table 3, the proportion of individuals who did not report that they needed gum treatment and did not have pockets $\geq 4 \mathrm{~mm}$, thus predicting the absence of pockets (NPV $\mathrm{Gum}_{\text {Gu }}$ ), ranged from $47 \%$ of $\geq 45$-year-old minority male smokers, who did not graduate from high school, had an annual income $<\$ 20,000$, and did not visit the dentist in the past year $\left(\mathrm{NPV}_{\mathrm{Gum}}=47 \%\right)$ to $98 \%$ of 18 - to 29 -year-old non-His- panic white female non-smokers who graduated from high school, had an annual income $\geq \$ 20,000$, and visited the dentist in the past year $\left(\mathrm{NPV}_{\mathrm{Gum}}=98 \%\right)$. Thus, the self-reported no need for gum treatment was a good predictor of not having pockets $\geq 4 \mathrm{~mm}$ for certain adults with specific characteristics.

\section{DISCUSSION}

Predictive values provide important information to clinicians ${ }^{5}$ researchers, and public health professionals when an individual's health status is based on a screening method such as self-report. The focus of our study was the investigation of the predictive values 
of self-reported periodontal need to identify periodontal condition at the individual level. Rather than modeling the prevalence of periodontal conditions, we modeled an individual's probability that his/her response predicted the presence/absence of periodontal conditions. These multivariable models depicted the independent role of sociodemographic and behavioral characteristics in the estimation of predictive values.

First, we will briefly discuss the influence of the prevalence of periodontal condition on predictive values. We presented examples that substantiated the general epidemiologic premise that the higher the disease prevalence in a group, the better the PPV, ${ }^{5}$ and the lower the disease prevalence (rarer), the better the NPV. ${ }^{12}$ Therefore, predictive values must be interpreted in the context of the prevalence of disease in the group under study. The influence of disease prevalence on the predictive values was evident because calculus was much more prevalent (found in $85 \%$ of all adults) than pockets $\geq 3 \mathrm{~mm}$ (present in $47 \%$ of all adults) and pockets $\geq 4 \mathrm{~mm}$ (present in only $11 \%$ of adults). The corresponding predictive values to identify those with and without calculus, pockets $\geq 3$ $\mathrm{mm}$, and pockets $\geq 4 \mathrm{~mm}$ were $P P V_{\text {Clean }}$ of $88 \%$ and $\mathrm{NPV}_{\text {Clean }}$ of $16 \%, \mathrm{PPV}_{\text {Gum }}$ of $61 \%$ and $\mathrm{NPV}_{\text {Gum }}$ of $54 \%$, and $P P V_{\text {Gum }}$ of $25 \%$ and $N P V_{\text {Gum }}$ of $90 \%$, respectively. Thus, PPV was a good measure for the more prevalent conditions and NPV was a good measure for the less prevalent conditions. Additional examples, for individuals with specific characteristics, are described below, with the inverse characteristic, e.g., smokers having good PPV and non-smokers having good NPV.

The high prevalence of calculus resulted in a high $\mathrm{PPV}_{\text {Clean. }}$. Simultaneously considering multiple characteristics in the final multiple logistic regression

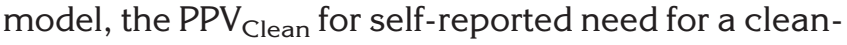
ing to predict the presence of calculus ranged from $70 \%$ to $99 \%$, depending on the individual's sociodemographic and behavioral characteristics. Thus, reporting that a cleaning is needed is a good measure for the presence of calculus. Conversely, the high prevalence of calculus results in a low $\mathrm{NPV}_{\text {Clean }}$, ranging from $1 \%$ to $38 \%$ when multiple characteristics were considered simultaneously. Thus, not reporting that a cleaning is needed is not a good measure for the absence of calculus.

The estimated predictive value (PPV Gum $)$ for the self-reported need for gum treatment to predict the presence of pockets $\geq 3 \mathrm{~mm}$ ranged from $37 \%$ to $90 \%$, depending on age, minority status, gender, smoking status, and whether they had visited the dentist in the past year. Similarly, the estimated predictive value $\left(N P V_{\text {Gum }}\right)$ for not reporting a need for gum treatment to predict the absence of pockets $\geq 4 \mathrm{~mm}$ ranged from $47 \%$ to $98 \%$. The better $N P V_{\text {Gum }}$ was found for youn- ger, non-Hispanic white female non-smokers who graduated from high school, had an annual income $\geq \$ 20,000$, and had an annual dental visit. Thus, reporting that gum treatment is needed is a good measure for the presence of pockets $\geq 3 \mathrm{~mm}$, and not reporting that gum treatment is needed is a good measure for the absence of pockets $\geq 4 \mathrm{~mm}$ for individuals with certain characteristics.

When assessing NPV $\mathrm{Gum}_{\text {, }}$ if it is close to $100 \%$, testing negative (i.e., self-reporting no need for gum treatment) is reassuring that pockets $\geq 4 \mathrm{~mm}$ are absent. However, if the NPV is $<100 \%$ by an amount comparable to the disease prevalence, ${ }^{16}$ as in this case, those with the specific characteristics may have pockets $\geq 4 \mathrm{~mm}$ but were not identified by this question. The justification for our approach is based on a recent study by Morrison et al. ${ }^{17}$ in the New England Journal of Medicine. Our findings of substantial improvement in the $P P V_{\text {Gum }}$ and $N P V_{\text {Gum }}$ for certain individuals with specific characteristics were similar to the improvement in the PPV when additional criteria were considered in a clinical prediction rule used by emergency medical technicians to stop resuscitation during cardiac arrest. ${ }^{17}$ The focus of Morrison et al.'s study was the high PPV (99.5\%) and specificity (90.2\%), rather than the low NPV (8.0\%) and sensitivity (64.4\%).

Next, we will compare our findings to those of previous studies. To the best of our knowledge, our study is the first investigation of the predictive value of the self-reported need for cleaning to identify those with calculus. One study ${ }^{18}$ that asked adolescents about "inflammation of gums" and "bleeding from gums during toothbrushing" concluded that neither was an adequate measure to screen individuals for gingivitis.

Our study reports on the clinical measures of periodontal condition; thus, it is not directly comparable to previous validation studies that used radiographs as the true measure of periodontal disease. ${ }^{6,8,9,19}$ This difference in study design is important because bitewing radiographs allow assessment of interproximal bone loss in the posterior segments only. The investigators addressed this weakness of using bitewing radiographs by reporting that most disease occurs on proximal sites. ${ }^{8}$ Data in a more recent report ${ }^{20}$ found that $27 \%$ (of all adults with $\geq 6 \mathrm{~mm}$ loss of attachment) to $29 \%$ (never smokers with $\geq 6 \mathrm{~mm}$ loss of attachment) had loss of attachment on the buccal site only. Although most of the disease occurred in the interproximal segments, the potential underestimation of $27 \%$ to $29 \%$ is relevant to validation studies.

An additional issue regarding the use of bitewings is that there is no information about the anterior segments. Joshipura et al. ${ }^{8}$ reported that $13 \%$ of Veterans Affairs Dental Longitudinal Study participants had anterior bone loss with no posterior bone loss. Thus, periodontal disease may be underestimated substantially 
when the source of data is bitewing radiographs. That is, an individual could be identified as not having periodontal disease when, in fact, periodontal disease is present in the right or left buccal or lingual posterior segments or in the right or left anterior segments.

A limitation of the NHANES is that dental examination data were derived from random half-mouth examinations measuring two sites per tooth, which underestimates the prevalence of periodontal disease. ${ }^{21,22}$ This limitation is mitigated, in large part, by the excellent correlation of 0.97 for the presence of calculus and 0.96 for the presence of pockets 3 to $6 \mathrm{~mm}$ deep detected by diagonal half-mouth versus whole-mouth examination. ${ }^{23}$ Thus, little information is lost if diagonal half-mouth data are collected instead of whole-mouth data for conditions that are prevalent. ${ }^{23}$ However, the correlation between halfmouth and whole-mouth data would be 1.00 for complete bilateral symmetry; therefore, some individuals with calculus and pockets may be misclassified as not having these conditions. We may be underreporting the true PPV and overestimating the true NPV. In other words, the true $\mathrm{NPV}_{\text {Gum }}$ for 18- to 29-year-old nonHispanic white female non-smokers who graduated from high school, had an annual income $\geq \$ 20,000$, and visited the dentist in the past year who reported that they did not need gum treatment and did not have pockets $\geq 4 \mathrm{~mm}$ may be less than the estimated $98 \%$.

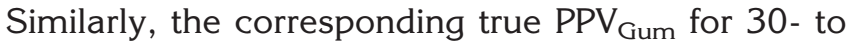
44-year-old minority female smokers who did not visit the dentist in the past year, reported that they needed gum treatment, and had pockets $\geq 3 \mathrm{~mm}$ may be greater than the reported $90 \%$.

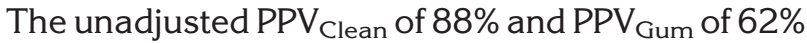
in our study are within the range of the PPV of administrative data (PPV ranged from $60 \%$ to $98 \%$ ) and the PPV of survey data (76\% to $98 \%$ ) to identify those with diabetes. This finding supports the further investigation of self-reported periodontal need as a good measure of periodontal disease because administrative databases and health surveys with similar predictive values were reported to do a relatively good job of identifying those with diagnosed diabetes. ${ }^{24}$

To the best of our knowledge, the application of multivariable logistic regression modeling to estimate predictive values that simultaneously takes into account sociodemographic and behavioral characteristics has not been reported previously. Similar study approaches are found in the medical field. In addition to the study by Morrison et al., ${ }^{17}$ the usefulness of focusing on PPV was reported for a study ${ }^{25}$ assessing the validity of questions to predict whether an individual had asthma. That study reported a "sophisticated statistical technique that models complex relationships between questions on the questionnaire to predict the required probability of asthma for each respondent in the population" to estimate PPV using an approach that ranked respondents based on multiple characteristics. The top $10 \%$ of a ranked community were higher-risk individuals. This approach, predicting the presence of a condition based on responses to questions, is similar to our approach of incorporating the characteristics directly into the estimation of the predictive values and our report of the range of estimated best and worst PPV and NPV.

A major strength of our study is that the multivariable analyses improved the predictive values. We used the beta coefficients in the multivariable logistic regression model to estimate the proportion of individuals who correctly self-reported their periodontal need to predict their periodontal condition based on multiple characteristics. For example, in Table 1, overall $P P V_{\text {Gum }}$ is $62 \%$ for all persons $\geq 18$ years of age, whereas in Table 3, $\mathrm{PPV}_{\text {Gum }}$ is $90 \%$ for 30 - to 44-year-old minority female smokers who did not visit the dentist in the past year. Conversely, the self-reported need for gum treatment was the least predictive of having pockets for $\geq 45$-year-old nonHispanic white male non-smokers who visited the dentist in the past year $\left(\mathrm{PPV}_{\mathrm{Gum}}=37 \%\right)$.

\section{CONCLUSIONS}

Based on the NHANES self-reported periodontal need, those who reported that they needed a cleaning were highly likely to have calculus, ranging from $70 \%$ to $99 \%$, depending on age, minority status, gender, smoking status, and visiting a dentist in the past year. In addition, $90 \%$ of certain adults who reported that they needed gum treatment had pockets $\geq 3 \mathrm{~mm}$, and $98 \%$ of adults with specific characteristics who did not report that they needed gum treatment did not have pockets $\geq 4 \mathrm{~mm}$. This approach to assess the validity of self-reported periodontal needs to identify the true periodontal condition of an individual, through estimated PPV, NPV, and the estimated probability for individuals with specific characteristics, has potential for further development. Our findings of inverse characteristics, such as smokers having good PPV and non-smokers having good NPV, indicated the influence of prevalence of conditions on predictive values. The application of multivariable logistic regression modeling to estimate predictive values that simultaneously takes into account sociodemographic and behavioral characteristics could be applied in future studies using additional questions to determine whether an expanded set of questions would provide better information regarding an individual's true periodontal condition. With access to dental care and dental examinations problematic for substantial portions of the United States population, these findings indicated the potential value of much more easily 
attainable questions identifying adults with calculus or pockets.

\section{ACKNOWLEDGMENT}

This research was support by the National Institutes of Health/National Institute of Dental and Craniofacial Research (grant 5K08DE016031-03).

\section{REFERENCES}

1. National Center for Health Statistics. National Health and Nutrition Examination Survey III. Documentation, codebook, and data files. Available at: http://www.cdc. gov/nchs/about/major/nhanes/nh3data.htm. Accessed January 27, 2007.

2. Beltran-Aguilar ED, Malvitz DM, Lockwood SA, Rozier RG, Tomar SL. Oral health surveillance: Past, present, and future challenges. J Public Health Dent 2003;63: 141-149.

3. Tomar SL, Taylor G, Slade GD. Development of selfreported measures for surveillance of periodontitis. J Dent Res 2006;85(Spec. Issue A):146.

4. Blicher B, Joshipura K, Eke P. Validation of selfreported periodontal disease: A systematic review. J Dent Res 2005;84:881-890.

5. Gordis L. Epidemiology, 3rd ed. Philadelphia: Elsevier Saunders; 2004:82-84.

6. Dietrich T, Stosch U, Dietrich D, Schamberger D, Bernimoulin J-P, Joshipura K. The accuracy of individual self-reported items to determine periodontal disease history. Eur J Oral Sci 2005;113:135-140.

7. Atchison KA, Dolan TA. Development of the geriatric oral health assessment index. J Dent Educ 1990;54: 680-687.

8. Joshipura KJ, Douglass CW, Garcia RI, Valachovic R, Willet WC. Validity of a self-reported periodontal disease measure. J Public Health Dent 1996;56:205-212.

9. Joshipura KJ, Pitiphat W, Douglass CW. Validation of self-reported periodontal measures among health professionals. J Public Health Dent 2002;62:115-121.

10. Buhlin K, Gustafsson A, Andersson K, Hakansson J, Klinge B. Validity and limitations of self-reported periodontal health. Community Dent Oral Epidemiol 2002; 30:431-437.

11. National Health and Nutrition Examination Survey 2003-2004. Documentation, codebook, and frequencies. MEC exam component: Oral health examination Recommendation of care/referral data, July 2006. Available at: http://www.cdc.gov/nchs/data/nhanes/ nhanes_03_04/ohxref_c.pdf. Accessed January 27, 2007.
12. Hennekens CH, Buring JE. Epidemiology in Medicine. Philadelphia: Lippincott Williams \& Wilkins; 1987:337.

13. Patrick DL, Cheadle A, Thompson DC, Diehr P, Koepsell T, Kinne S. The validity of self-reported smoking: A review and meta-analysis. Am J Public Health 1994;84:1086-1093.

14. Shah B, Barnwell B, Bieler G. SUDAAN User's Manual, release 8.0. Research Triangle Park, NC: Research Triangle Institute; 2001.

15. Hosmer DW, Lemeshow S. Applied Logistic Regression, 2nd ed. New York: John Wiley and Sons; 2000:85-88.

16. Rothman KJ, Greenland S. Modern Epidemiology, 2nd ed. Philadelphia: Lippincott-Raven Publisher; 1998: 509-510.

17. Morrison LJ, Visentin LM, Kiss A, et al. Validation of a rule for termination of resuscitation in out-of-hospital cardiac arrest. N Engl J Med 2006;355:478-487.

18. Kallio P, Nordblad A, Croucher R, Ainamo J. Selfreported gingivitis and bleeding gums among adolescents in Helsinki. Community Dent Oral Epidemiol 1994;22:277-282.

19. Pitiphat W, Garcia RI, Douglass CW, Joshipura KJ. Validation of self-reported oral health measures. J Public Health Dent 2002;62:122-128.

20. Fisher MA, Taylor GW, Tilashalski KR. Smokeless tobacco and severe active periodontal disease, NHANES III. $J$ Dent Res 2005;84:705-710.

21. Beck JD, Caplan DJ, Preisser JS, Moss K. Reducing the bias of probing depth and attachment level estimates using random partial-mouth recording. Community Dent Oral Epidemiol 2006;34:1-10.

22. Kingman A, Morrison E, Löe H, Smith J. Systematic errors in estimating prevalence and severity of periodontal disease. J Periodontol 1988;59:707-713.

23. Hunt RJ. The efficiency of half-mouth examinations in estimating the prevalence of periodontal disease. J Dent Res 1987;66:1044-1048.

24. Saydah SH, Geiss LS, Tierney E, Benjamin SM, Engeldau M, Brancati F. Review of the performance of methods to identify diabetes cases among vital statistics, administrative, and survey data. Ann Epidemiol 2004;14:507-516.

25. Hirsch S, Frank RL, Hazell M, Frank PI. Screening for asthma by population ranking: A validation study. Ann Epidemiol 2005;15:64-70.

Correspondence: Dr. Monica A. Fisher, Case Western Reserve University, 10900 Euclid Ave., Cleveland, OH 44106-4905. Fax: 216/368-0145; e-mail: monica.fisher@case.edu.

Accepted for publication January 27, 2007. 